\title{
A câmera diegética: legibilidade narrativa e verossimilhança documental em falsos found footage de horror ${ }^{1}$
}

|IIIIIIIIIIIIIIIII: Rodrigo Carreiro

1. Uma versão preliminar deste ensaio foi apresentada no GT de Estudos de Cinema, Fotografia e Audiovisual do XXII Encontro Anual da Compós, na Universidade Federal da Bahia, em Salvador, em junho de 2013.

2. Professor do Programa de Pós-Graduação em Comunicação da Universidade Federal de Pernambuco. Doutor e mestre em Comunicação pela UFPE. Atua principalmente nas áreas de teoria e história do cinema, com ênfase na análise fílmica, nos estudos dos gêneros fílmicos e nos estudos do som. Tem interesse especial na pesquisa da estilística cinematográfica e no cinema de horror. E-mail: rcarreiro@gmail.com 


\title{
Resumo
}

Falsos documentários de horror codificados como found footage têm sido massivamente realizados nas últimas duas décadas. Filmar um roteiro de ficção com a textura estilística de um documentário exige restrições criativas, a fim de impor a imagens e sons o efeito de real presente em material filmado de forma amadora. Este ensaio examina padrões recorrentes de estilo usados para conjugar legibilidade narrativa e verossimilhança documental, combinação exigida pela presença de dispositivos de registros no diegese.

\section{Palavras-chave}

Horror, estilística, found footage, falso documentário, câmera diegética.

\begin{abstract}
Fake found footage horror films have been massively made in the last two decades. To shoot a fictional script and give to it the texture of a documentary, a filmmaker has to deal with a number of creative restrictions in order to impose to images and sounds an effect of reality present in amateur footage. This essay examines recurring patterns of style, in this subgenre of movies, which have been used to combine narrative clarity and documental verisimilitude - a combination imposed by the presence of recording devices on the diegesis.
\end{abstract}

Keywords Horror film, stylistics, found footage, mockumentary, diegetic camera. 
3. Realizado ao custo de US\$ 30 mil, A bruxa de Blair faturou um total de US\$ 246 milhões nas bilheterias, se tornando o quarto filme de horror mais visto de todos os tempos e o filme de melhor relação custo/ arrecadação feito até o momento.

4. Alguns pesquisadores preferem usar outros jargões, como Point of view (POV) films ou discovered footage films (termo criado por David

Bordwell), para evitar confusões com outro gênero fílmico também chamado de found footage, praticado por cineastas como Péter Forgács,

Harun Farocki e Martin Arnold, e que consiste, em sua maioria, da produção de documentários experimentais a partir da colagem e da ressignificação de imagens de arquivo preexistentes.

\section{Introdução}

A produção de falsos documentários de horror codificados como found footage, que se tornou massiva nas últimas duas décadas, tem concretizado um fenômeno cinematográfico digno de interesse. Esse tipo de filme, híbrido de ficção e documentário, começou a ser explorado em meados dos anos 1970. O formato foi cristalizado pelo longa-metragem italiano Canibal holocausto (Cannibal holocaust, Ruggero Deodato, 1980), marco fundamental do falso documentário no cinema (PIEDADE, 2007, p. 376). Passou então a ser explorado, ainda de forma tímida e esparsa (BORDWELL, 2012). Quase vinte anos se passaram antes que o falso found footage se tornasse um formato popular entre cineastas, o que ocorreu após a boa recepção de crítica e público ao filme A bruxa de Blair (The Blair witch project, Eduardo Sánchez e Daniel Myrick, 1999)³. A partir de então, a produção de falsos found footage explodiu em quantidade, a ponto de parte da crítica jornalística dos Estados Unidos criar uma alcunha para esse tipo de produção: found footage genre ${ }^{4}$.

De modo geral, os filmes chamados dessa forma possuem enredos ficcionais que utilizam deliberadamente procedimentos estilísticos e/ou narrativos normalmente associados ao documentário, muitas vezes com a intenção de enganar o espectador quanto ao caráter ontológico de suas imagens e sons. Pode-se afirmar, parafraseando Fernão Pessoa Ramos (2008, p. 27), que em filmes de falso found footage a utilização deliberada do estilo documental confunde a fruição do espectador sobre a intenção do cineasta - e é na interação 
5. A estatística relativa aos lançamentos cinematográficos inclui apenas longas-metragens presentes no banco de dados do IMDb.

A compilação feita para minha pesquisa contém mais de 230 falsos documentários codificados como found footage e pode ser conferida aqui: http://www.imdb.com/list/ tagV4JrrckY/. entre esses dois pilares que se dá a percepção de um filme pelo espectador, no que se refere ao seu discurso ontológico.

Embora não seja possível afirmar quantos filmes de found footage codificados como documentários foram produzidos desde a consolidação do formato, é seguro que estamos falando um número superior a duas centenas, segundo dados obtidos em bancos de registro cinematográfico disponíveis na internet (Internet Movie Database, Box Office Mojo e Amazon, entre outros). Esses títulos foram realizados em países como Austrália, Noruega, Dinamarca, Estados Unidos, Japão, Índia, Espanha, Bélgica, França, Costa Rica, México e Brasil, e sob modos distintos de produção. O formato já foi utilizado também em quatro minisséries de TV e quatro games eletrônicos5. O número de lançamentos de ficções codificadas como documentários, vinculadas sobretudo ao gênero fílmico do horror, continua aumentando.

De fato, o interesse do público de cinema por filmes constituídos parcial ou inteiramente por imagens (e sons) de textura amadora, íntimas ou caseiras parece estar crescendo consideravelmente nas últimas duas décadas. Isso nos levar a supor que a consolidação do falso documentário de horror feito como found footage consiste em uma das múltiplas faces de um fenômeno mais amplo e culturalmente significativo do que a consolidação de um subgênero fílmico específico.

Acadêmicos de origens diferentes têm refletido sobre esse fenômeno, a partir de múltiplas abordagens teóricas (ODIN, 1995; WEST, 2005; FELDMAN, 2008; BRASIL; MIGLIORIN, 2010; HELLER-NICHOLAS, 2011; INGLER, 2011; CÁNEPA; FERRARAZ, 2013). A ressignificação de filmes de família, o uso de vídeos disponíveis na Internet dentro de trabalhos audiovisuais, a popularidade de imagens amadoras, os fenômenos midiáticos nascidos de vídeos caseiros postados no YouTube, a forte e crescente tendência da aceitação de erros técnicos - até mesmo a preferência por imagens que contenham esses erros, como índices de um realismo nem sempre verdadeiro - e a espetacularização de imagens e sons da intimidade constituem temas que integram um debate mais amplo sobre novos regimes de visualidade que privilegiam imagens não profissionais. 
Essas são algumas das razões existentes para que um cineasta opte por fazer um filme de ficção codificado como documentário de found footage (o baixo custo de produção, que não exige gastos altos com equipamentos de filmagem ou atores famosos, é outra razão importante). De qualquer forma, a decisão de filmar um roteiro dessa forma obriga um diretor de cinema a se defrontar com uma série de restrições criativas que ele precisará driblar, se quiser que seu filme tenha a clareza narrativa de uma ficção tradicional somada à aparência de realidade de um documentário.

Conjugar os dois princípios contraditórios da narração cinematográfica - a legibilidade narrativa e a verossimilhança documental - parece ser o maior desafio de qualquer cineasta que deseja experimentar com o formato. Dar ao filme a aparência de um documento histórico é parte essencial da prática criativa, pois a textura imagética e sonora exerce papel importante na produção, dentro da moldura ficcional, de um efeito de real (BARTHES, 1972, p. 43) necessário para incluir o produto dentro da demanda por realismo (ainda que simulado) ao qual nos referimos. Nesse sentido, a mimetização das convenções e códigos oriundos do documentário constitui prática importante na produção do efeito do real, pois esse gênero de filmes "aparenta ter a capacidade de retratar o mundo da forma mais acurada e realista possível" (ROSCOE; HAIGHT, 2001, p. 23).

Nos falsos found footage existe, pois, uma necessidade estilística que desestabiliza a relação de superioridade da legibilidade sobre a verossimilhança que existe comumente no cinema de ficção tradicional, conforme apontado por Rick Altman (1992). Nos filmes de ficção codificados como found footage, ambos os princípios são igualmente importantes.

A decisão de realizar um filme de ficção com uso da estilística do documentário de found footage não é tão simples quanto parece. Não se pode transformar um roteiro planejado como uma ficção tradicional numa produção deste tipo. Uma série de restrições de ordem narrativa e estilística, especialmente quanto à representação visual e sonora do espaço físico e geográfico, dos pontos de vista visual e narrativo e do ponto de escuta, se impõe. Essas restrições 
estão, em geral, relacionadas direta ou indiretamente ao conflito entre legibilidade e verossimilhança, cujo equilíbrio é bastante diferente do almejado numa ficção tradicional. O objetivo deste ensaio consiste em identificar e analisar essas restrições, examinando como os diretores dos falsos found footage têm lidado com elas.

\section{A câmera diegética}

A mais destacada característica do falso found footage de horror - aquela que influencia e define todos os padrões recorrentes de estilo associados a este ciclo de produção - tem relação direta com o citado conflito entre legibilidade e verossimilhança, e consiste na presença de um aparato de captação de imagem e sons dentro da diegese. Daqui em diante, vamos chamar esse aparato de câmera diegética. Bill Nichols descreve assim o impacto da presença da câmera na audiência de um documentário:

\footnotetext{
A presença da câmera "na cena" atesta sua presença no mundo histórico. Isso confirma a sensação de comprometimento, ou engajamento, com o imediato, o íntimo, o pessoal, no momento em que ele ocorre. Essa presença também confirma a sensação de fidelidade ao que acontece e que pode nos ser transmitida pelos acontecimentos, como se eles simplesmente tivessem acontecido, quando, na verdade, foram construídos para terem exatamente aquela aparência (NICHOLS, 2005, p. 150).
}

A câmera diegética demarca a principal diferença narrativa do subgênero em relação à ficção tradicional, na qual os personagens não percebem a existência de dispositivos de registro de imagens e sons. Na tradição narrativa do cinema ficcional, este aparato costuma ter o dom da ubiquidade: o cineasta é capaz de narrar a progressão dramática do enredo a partir de múltiplos pontos de vista, tanto objetivos quanto subjetivos, de acordo com os desejos e necessidades da instância narradora.

A presença da câmera diegética, obrigatória para imprimir à narração o efeito de real pretendido, impõe uma série de restrições 
ao ato narrativo, tendo inclusive implicações no desenvolvimento dramatúrgico. Na ficção tradicional, por exemplo, a ubiquidade do narrador oculto implica este "poder mover" livremente o dispositivo de registro, escolhendo a todo tempo o posicionamento de câmera mais favorável, em termos de geografia, perspectiva e ponto de vista, para que o espectador compreenda mais rapidamente a progressão do enredo. A câmera pode ser posicionada inclusive em lugares fisicamente inacessíveis da diegese, já que ela existe e é operada em uma dimensão puramente narrativa, onipresente e não sensível aos eventos diegéticos. A mesma afirmação vale para o gravador de sons.

Já no falso filme de found footage, a seleção da localização espacial e do ponto de vista de registro das ações é limitada pela fisicalidade do dispositivo fílmico. Em geral, um (ou mais de um) personagem precisa operar o equipamento. Mas, mesmo nos casos em que a câmera funciona sem ser manuseada por alguém - caso, por exemplo, dos sistemas de vigilância usados nos quatro filmes da série Atividade paranormal, produzida entre 2007 e 2012 nos Estados Unidos - o ângulo de visão (e, em muitos casos, o ponto de vista narrativo) não pode ser alterado a cada plano, à livre escolha do narrador. É precisamente por isso que o sistema plano/contraplano para o registro de diálogos, tão comum na ficção tradicional, só pode existir num falso found footage se houver mais de uma câmera presente na cena.

Além disso, a consciência da presença do dispositivo de registro dentro da diegese influencia, como se sabe, o comportamento das pessoas que estão sendo filmadas. Nesse sentido, eles se tornam duplamente atores, pois mesmo dentro da diegese sabem que estão representando versões de si próprios para a câmera, algo que não ocorre na narração tradicional, em que a câmera oculta aos personagens impõe uma qualidade voyeur ao registro (os personagens não sabem que estão sendo filmados). Este tópico tem sido problematizado por muitos cineastas, como Werner Herzog em O homem urso (Grizzly man, 2005) e Eduardo Coutinho em Jogo de cena (2007), apenas para citar dois exemplos, e também por teóricos (NICHOLS, 2005; RAMOS, 2008; GAULTIER, 2011). 
Alguns falsos found footage de horror, como Diário dos mortos (Diary of the dead, George Romero 2007), também discutem a questão da representação (e da autorrepresentação) numa sociedade cada vez mais midiática. Essas questões, contudo, escapam ao objetivo deste ensaio.

Do ponto de vista estilístico, a presença na diegese de dispositivos de registro possui implicações que interferem de modo bastante sensível no conflito entre os princípios da legibilidade e da verossimilhança. Em primeiro lugar, existe a obrigatoriedade de que pelo menos um personagem opere a câmera. Mesmo que este personagem não esteja com o equipamento nas mãos o tempo inteiro, ele ainda precisa ligá-lo, desligá-lo e cuidar para que ele esteja em funcionamento nos momentos dramaticamente relevantes, para que o espectador não seja privado de nenhuma informação essencial para a compreensão do enredo.

De fato, a câmera (e também o gravador de sons, se este for um dispositivo autônomo) cria uma conexão oculta entre as dimensões diegética e narrativa, ou entre determinados personagens e a instância narradora. Em outras palavras, o personagem que opera a câmera deverá, na maior parte do tempo, obedecer a necessidades que não são verdadeiramente dele, mas sim do narrador. Em cada cena, este personagem terá que estar mais ou menos próximo do (e com a câmera apontada para o) lugar onde se concentra o foco principal de interesse dramatúrgico, a fim de garantir a legibilidade daquela ação pelo espectador. Por outro lado, o personagem em questão não pode agir de modo excessivamente mecânico, não natural, assumindo uma preocupação exclusivamente narradora, pois sua presença na diegese o torna sensível aos eventos que ameaçam a estabilidade dramática.

Tomemos como exemplo o filme costa-riquenho El sanatorio (Miguel Alejandro Gomez, 2010) em que uma equipe de cineastas investiga aparições sobrenaturais num prédio de hospital abandonado. Quando os fantasmas surgem, o operador de câmera não pode permanecer registrando a ação de modo impassível. Isso seria normal numa ficção tradicional, em que a câmera não existe na diegese e, portanto, seu operador não está ameaçado pelos fantasmas, 
podendo se preocupar exclusivamente com a legibilidade da ação. Num falso found footage, o personagem com a câmera precisa reagir como alguém que sofreria consequências físicas se não fugisse. Por isso, em El sanatorio, o operador de câmera corre aos tropeções, grita e se desespera. Ele sacode a câmera, a imagem treme, perde o foco, sofre com interferências elétricas, passa por regiões sem luz; ou seja, torna-se instável - é essa instabilidade, afinal, que introduz e garante a aparência de registro documental, produzindo o efeito de real que dá o aspecto de um documentário ao filme (RAMOS, 2008, p. 25) e, por consequência, providencia a verossimilhança necessária ao registro, aproximando sua estética daquela oriunda de um documento histórico. Este exemplo se aplica a, virtualmente, todos os falsos documentários codificados como found footage de horror, cuja estilística busca intencionalmente reproduzir, por meio de uma variedade de técnicas de manipulação de imagem e som, os padrões de estilo de um documentário real.

A porção mais facilmente reconhecível das técnicas que garantem a impressão de instabilidade da tomada na banda imagética dos falsos found footage está na reprodução intencional de erros técnicos, supostamente oriundos da impossibilidade de manuseio da câmera de maneira tecnicamente correta. Em um documentário real, especialmente quando os eventos registrados são ocasionais e impossíveis de repetir, não existe a possibilidade de corrigir movimentos de câmera, iluminação deficiente e detalhes técnicos em geral. Daí a câmera tremida, riscos na imagem e tomadas em completa escuridão que podemos ver em filmes como Apollo 18 (Gonzalo López-Gallego, 2011), A bruxa de Blair, Desaparecidos (David Schürmann, 2011), O caçador de Troll (Trolljegeren, André Øvredal, 2010), The Poughkeepsie tapes (John Erick Dowdle, 2007) e tantos outros.

A verossimilhança, portanto, ganha importância dentro da estilística desse tipo de filme, mas não a ponto de eliminar a legibilidade do enredo. Essa necessidade continua a existir. O diretor precisa encontrar maneiras de criar o efeito de real necessário sem perder totalmente a legibilidade. Se o cameraman de El sanatorio largasse a câmera quando fosse atacado por um fantasma (algo 
normal se estivéssemos falando de um documentário verdadeiro, no qual a preocupação do operador de câmera em garantir a própria sobrevivência seria evidentemente maior do que com realizar o registro do fato), estaria agindo de modo perfeitamente coerente, mas o espectador não saberia o que aconteceu com ele e com os demais personagens do filme. A plateia seria privada de informações essenciais à progressão do enredo, algo que não pode ocorrer, especialmente num filme de ficção.

Uma das maneiras de garantir a impressão de verossimilhança sem que se perca a legibilidade da imagem consiste na organização cuidadosa da mise-en-scène, sem que, no entanto, essa organização seja claramente perceptível pelo espectador. Assim, quando um personagem de um falso found footage começa a correr para fugir de um monstro, fantasma ou psicopata, por exemplo, ele nunca desliga ou abandona o equipamento de filmagem. Continua a fazer o registro. Dessa forma, são os erros técnicos sensíveis ao espectador, na imagem e no som, que garantem a impressão de verossimilhança: a câmera balança, desenquadra a imagem, aponta para lugares sem luz. Essas técnicas introduzem áreas de ilegibilidade imagética que normalmente não são aceitas na ficção cinematográfica tradicional, mas se mostram fundamentais em falsos documentários codificados como found footage.

Assim, um dos desafios narrativos mais básicos do cineasta consiste em providenciar maneiras de prover a plateia continuamente com informações sobre a progressão dramática, equilibrando o encadeamento narrativo incessante com a instabilidade da tomada que garante a aparência documental. Muitas vezes a câmera reenquadra a ação apenas por alguns instantes, o suficiente para que o espectador reconheça o que ocorre (em filmes estadunidenses, em particular, é bastante comum que mortes e ações violentas sejam eliminadas do filme justamente nas lacunas narrativas geradas pelo uso dessa técnica, que poderíamos chamar de mostra-e-esconde).

O final de A bruxa de Blair, quando a câmera permanece jogada no chão sem que se possa ver o que ocorre com os personagens fora do quadro, antes que o aparelho quebre e pare de registrar imagens, é um exemplo clássico dessa técnica. No filme espanhol [Rec], 
dirigido em 2007 por Paco Plaza e Jaume Balagueró, a mesma técnica é repetida em dois momentos distintos, sendo o primeiro no meio do filme (a câmera é largada no chão por alguns instantes pelo cameraman), e o segundo na sequência final, quando falta luz no prédio onde ocorre a ação. Nos dois casos, durante alguns minutos, o espectador continua acompanhando o desenrolar da ação dramática exclusivamente por meio do som (diálogos e ruídos), cuidadosamente planejado - e devidamente sujo, incluindo erros técnicos como saturação do sinal do microfone, para prover a verossimilhança necessária (TARRAGÓ, 2010).

A estratégia de organizar a mise-en-scène de forma a mostrar parte da ação dramática e esconder outra tem sido historicamente muito eficaz no cinema de horror. Nos falsos found footage, ela tem sido utilizada com ênfase ainda maior. Além de gerar tensão e mistério, essa técnica também pode garantir a verossimilhança documental sem que a legibilidade narrativa seja perdida. Um dos exemplos mais claros e criativos do uso dessa estratégia aparece em Atividade paranormal 3 (Paranormal activity 3, Henry Joost e Ariel Schulman, 2011). Em certo ponto do filme, quando as assombrações começam a chamar a atenção do dono da casa onde se passa a ação dramática, este decide investigar melhor o caso. Como possui uma produtora de vídeo (protagonistas que possuem profissões ligadas ao cinema são muito frequentes nesse tipo de filme, como veremos adiante, porque ajudam a justificar para a plateia o uso intermitente e a operação tecnicamente adequada de equipamentos de filmagem), ele decide instalar câmeras em toda a casa.

Para cobrir os dois ambientes da sala, o protagonista instala uma das câmeras disponíveis sobre a base de um ventilador, que é mantido girando em elipses de 180 graus durante toda a noite. Esse movimento de câmera proporciona ao diretor do filme a oportunidade de pregar dois ou três sustos no espectador, mantendo-o em constante estado de expectativa e tensão sempre que as imagens fornecidas por essa câmera aparecem - afinal, nunca é possível antecipar o que invadirá o quadro no instante seguinte, quando a câmera desvela uma parte da imagem antes inacessível. A técnica se mostra altamente eficaz para gerar o afeto 
do horror, fundamental em filmes do gênero, sem que se perca a verossimilhança documental necessária. Como nos exemplos anteriores, o uso dessa técnica é imposto e moldado pelo princípio da câmera diegética.

Esse jogo de mostra-e-esconde também pode incluir o uso da escuridão como forma de realçar a tensão de certas cenas sem que a verossimilhança seja perdida. Muitos filmes incluem momentos dramáticos em que a luz é repentinamente cortada ou reduzida por circunstâncias diegéticas extraordinárias (como explosões e curtoscircuitos elétricos), de modo que a visão da plateia é interrompida. Momentos de escuridão absoluta, sem que se possa enxergar nada, aparecem em A bruxa de Blair e The tunnel (Carlo Ledesma, 2011), por exemplo. Em muitos filmes, como Cloverfield (Matt Reeves, 2008), [Rec] e O caçador de Troll, câmeras especiais com visão infravermelha são manipuladas pelos personagens. Esse recurso garante que o espectador seja capaz de continuar recebendo informações narrativas por meio da banda de imagem do filme, em particular nos casos em que o som não pode, sozinho, garantir a legibilidade de toda a ação dramática.

Outro padrão recorrente ligado ao princípio da câmera diegética está na aparência amadora de muitas imagens. Quando os personagens dos filmes não têm acesso fácil a equipamentos profissionais de captação de imagens (câmeras digital de alta definição ou de $35 \mathrm{~mm}$ ), muitas vezes registram os acontecimentos através de dispositivos amadores: câmeras de VHS (Atividade paranormal 3, The Poughkeepsie tapes, Alien abduction: incident in Lake County, dirigido por Dean Alioto em 1998), câmeras de vídeo digital de baixa resolução (como Cloverfield e Poder sem limites Chronicle, feito em 2012 por Josh Trank), câmeras de telefones celulares (Diário dos mortos e Ragini MMS, filme indiano dirigido em 2011 por Pawan Kripalani), câmeras de vigilância (Atividade paranormal 2, Tod Williams, 2010) e assim por diante. A antologia V/H/S (2012), que reúne seis histórias curtas dirigidas por diferentes diretores, recebeu até mesmo o nome de um formato de imagens em movimento de qualidade técnica inferior. Esses formatos amadores possuem, em muitos casos, textura sem profundidade, 
falta de definição de contornos, cores gastas. A aparência amadora também reforça, por meio da instabilidade da tomada, o senso de verossimilhança e o efeito de real (BARTHES, 1972, p. 43) pretendido pelos cineastas.

Do ponto de vista narrativo, a presença do aparato de registro de imagens e sons na diegese provoca o surgimento de outros padrões recorrentes. Um deles é a existência obrigatória de um (ou mais) personagem que manuseia a câmera. Por razões de ordem narrativa, esse personagem costuma configurar aquilo que alguns pesquisadores do cinema de horror, como Carol J. Clover (1992), apontam como elemento importante para garantir a indexação do filme como exemplar do gênero: a existência de pelo menos um personagem sobrevivente, que presencia de perto os fatos trágicos narrados no enredo e consegue permanecer vivo no final, tendo seu ponto de vista, na maioria das vezes, utilizado pela instância narrativa para gerar empatia entre público e personagens. Como forma de justificar a boa qualidade de imagens e sons capturados por esse sobrevivente, em muitos filmes de found footage eles são profissionais que atuam na indústria audiovisual: operadores de câmera, técnicos de áudio e editores de som e imagem têm presença constante em filmes como [Rec], A bruxa de Blair, Diário dos mortos, O caçador de Trolls, The tunnel, Fenômenos paranormais e $O$ sanatório, entre outros.

David Bordwell (2012) observa que a necessidade de evitar a ubiquidade da câmera, tradicional na ficção cinematográfica, leva muitos diretores de filmes de found footage a transformar equipes de filmagem em protagonistas dos enredos. Todos os filmes citados no parágrafo anterior se enquadram nessa observação. Esse padrão narrativo serve não apenas para justificar a boa qualidade de imagens e sons, mas também para oferecer uma explicação crível (parcialmente, pelo menos) para o fato de os personagens permanecerem registrando os eventos ocorridos na diegese, mesmo quando têm suas próprias vidas ameaçadas.

Por outro lado, como os personagens que operam diretamente o aparato de filmagem não podem ser mostrados com frequência (a não ser que exista uma segunda câmera, o que de fato ocorre 
em alguns filmes, como A bruxa de Blair e Atividade paranormal 2 ), esse padrão traz consigo um problema: sem poder registrar visualmente as reações afetivas do operador de câmera na maior parte do tempo, o espectador tem dificuldade em criar empatia com seus desejos, emoções e medos. É por isso que em muitos filmes - entre os quais $\mathrm{O}$ sanatório, $\mathrm{O}$ caçador de Trolls, [Rec] e The tunnel - o cameraman é um sobrevivente, mas não um personagem importante para a narrativa.

No que se refere à estilística praticada pelos diretores desses filmes, alguns dos padrões que mais chamam a atenção contrariam tendências do cinema contemporâneo praticado em Hollywood, como o uso massivo de planos-sequência (em contraposição à montagem acelerada que vemos em filmes mainstream) e o baixo número de planos em close-up de rostos. De modo geral, os falsos found footage de horror compartilham entre si uma série de escolhas estilísticas mais ou menos comuns, relacionadas à mise-en-scène: tomadas longas e sem cortes, encenação em profundidade (a ação ocorre predominantemente num eixo perpendicular, e não paralelo à câmera) e predomínio de planos gerais, ao invés de close-ups. Todas essas ferramentas de estilo são usadas com frequência maior nos falsos documentários do que em enredos de ficção filmados da forma tradicional.

A predominância de planos gerais induz os filmes a apresentar, como característica associada, um baixo número de close-ups de rostos. Os dois padrões visuais advêm de uma terceira característica: a montagem visual dos falsos found footage tende a ser mais lenta, com planos de maior duração do que em filmes de narrativa tradicional. Pode-se comprovar esse padrão recorrendo à pesquisa de Barry Salt (2009), que registra em estatísticas a tendência de aceleração progressiva da montagem visual ocorrida a partir da virada entre os anos 1950 e 1960, quando a média de duração de um plano estava entre oito e nove segundos, e o final dos anos 1990, momento em que a média caiu para quatro segundos por plano (SALT, 2009, p. 358). Essa média tende a ser muito mais alta em filmes de found footage, e a explicação para isso tem origem também no princípio da câmera diegética: como a maior parte dos filmes possui apenas 
um aparato registrando a ação dramática, o diretor não pode variar o enquadramento ao longo da cena, procedimento que destruiria a verossimilhança documental. [Rec], por exemplo, contém apenas 72 tomadas, o que resulta numa média de 57 segundos por plano (há um plano com 17 minutos e 51 segundos de duração). Mesmo A bruxa de Blair, que tem duas equipes autônomas registrando os eventos com aparatos distintos, tem média de 15 segundos por plano, duração quase quatro vezes mais alta do que a média de plano de um filme de ficção tradicional.

Pelo mesmo motivo, o número de close-ups de rostos é muito menor em falsos documentários de found footage. Num longametragem contemporâneo, o número de tomadas que focalizam um rosto humano em primeiro plano costuma girar em torno de 50\% (CARREIRO, 2011, p. 209), seguindo uma tendência da poética da continuidade intensificada (BORDWELL, 2005, p. 119). Porém, se o filme é construído com tomadas longas nas quais a câmera toma parte da ação e não para de mexer, é natural que haja poucos close-ups. Bordwell (2012) nota que as conversas entre dois personagens, que na ficção tradicional são filmadas normalmente no clássico sistema plano/contraplano, em falsos found footage de horror são enquadradas quase sempre através de um único plano geral ou médio que reúne os dois personagens com falas. Uma alternativa a essa estratégia consiste em filmar todo o diálogo num plano médio, sem cortes, em que um dos personagens é enquadrado sozinho, da cintura para cima, enquanto o segundo ator permanece fora do quadro, às vezes operando a câmera. Esse tipo de enquadramento lembra uma entrevista filmada para a TV e aparece com certa constância, porque boa parte dos falsos documentários de found footage, não custa lembrar, mostra equipes de TV filmando reportagens ou documentários.

Mais um padrão de estilo relacionado à presença da câmera na cena é a tendência para a encenação em profundidade, que consiste no estabelecimento de um eixo de ação física, para os atores, perpendicular ao eixo da câmera, de forma que a ação física dos personagens tende a se concentrar mais sobre esse eixo vertical e menos no eixo paralelo (e horizontal) à câmera. Esse 
tipo de encenação, chamada de "recessiva" por David Bordwell (2008, p. 219), remonta às décadas de 1930 e 1940, quando foi popularizada por diretores como Jean Renoir, Kenji Mizoguchi e Orson Welles. Quando realizada de modo cuidadoso, como em [Rec] e A bruxa de Blair, a encenação recessiva reduz a necessidade de movimento lateral da câmera, que produz muitas vezes borrões de imagem quase ilegíveis, conhecidos no jargão cinematográfico como chicotes. Desse modo, a encenação em profundidade torna a imagem mais estável, ampliando sua legibilidade sem afetar a verossimilhança.

No que se refere ao uso do som nesses filmes, o princípio da câmera diegética é igualmente decisivo para as escolhas estilísticas efetuadas pelos cineastas. Na maioria dos falsos found footage não há música extradiegética, procedimento comum na ficção tradicional que reduz a verossimilhança documental. Além disso, imperfeições oriundas da manipulação apressada na captação do som direto (que, evidentemente, não pode ser sanada como em uma ficção, já que as cenas de um documentário não podem ser repetidas) são valorizadas: sinal saturado do microfone, vozes sobrepostas, rangidos, chiados, microfonias, sons de respiração dos atores etc. Muitas vezes, erros derivados de técnicas deficientes de captação sonora são construídos cuidadosamente em estúdio, como no caso de [Rec] (TARRAGÓ, 2010). No exemplo citado, essa estratégia permitiu a construção de uma textura de imperfeição sonora sem que se perdesse a clareza narrativa, já que a construção dos defeitos de captação do som na pós-produção permitiu à equipe de editores de som decidir em quais momentos do enredo as vozes dos atores poderiam ficar ilegíveis sem que a plateia fosse privada de informações dramáticas relevantes.

\section{Conclusão}

Os padrões recorrentes de estilo descritos acima derivam do conflito entre verossimilhança documental e legibilidade narrativa. Como vimos, é a presença de um dispositivo de registro de imagens e sons dentro da diegese que impõe aos cineastas a necessidade de uma abordagem estilística distinta daquela aplicada a filmes tradicionais. 
Um falso documentário de horror codificado como found footage precisa simular a aparência de um documentário verdadeiro, a fim de inscrever nos sons e imagens apresentados à plateia um efeito de real. Esse efeito de real será tão mais forte quanto mais parecida com um documentário verdadeiro for a estilística do filme em questão, porque "o uso de técnicas de documentário acrescenta ao gênero do horror uma aura forte de realidade" (RHODES, 2002).

De fato, o conflito entre legibilidade e verossimilhança atravessa todo tipo de filme, como assinala Rick Altman (1992). Numa ficção tradicional, a ubiquidade da câmera garante que a legibilidade leve alguma vantagem nesse conflito, pois os cineastas têm a possibilidade de variar o ângulo de câmera, o ponto de vista narrativo e o ponto de escuta sonoro para permitir que o público compreenda as informações narrativas sem interrupções. No entanto, a ubiquidade consiste em uma convenção cinematográfica, uma ferramenta narrativa que não possui lastro na realidade, mas cujo uso contínuo tornou-a aceitável pelo espectador, de modo que naturalizamos o princípio de que, em uma ficção comum, imagens e sons nos serão apresentadas do ângulo mais favorável possível à compreensão do enredo.

Nos falsos documentários de horror, conforme pudemos demonstrar, essa abordagem contém uma cilada. A ubiquidade do aparato de registro de sons e imagens costuma garantir qualidade técnica excelente, e isso pode arruinar o caráter de documento histórico desses registros. O caráter documental é crucial para alimentar a ilusão (ainda que consentida) do público a respeito de estar olhando para uma janela que acessa o real. Por isso, é natural que os profissionais que realizam esse tipo de filme ressaltem certo grau de imperfeição técnica na apresentação das informações visuais e sonoras. Os padrões recorrentes analisados nesse ensaio, que constituem a estilística dos falsos found footage, derivam dessa necessidade.

Praticamente todos os falsos documentários produzidos nos últimos 20 anos se pretendem fazer passar por registros genuínos de algum evento extraordinário, fruto de um modelo de produção - muitas vezes amador ou mesmo leigo - baseado na observação 
6. Os documentários reflexivos, poéticos ou performáticos - outros modos de representação classificados por Nichols - costumam apresentar forte caráter autoconsciente, propriedade que muitas vezes obscurece o efeito de real importante para gerar na plateia o afeto do horror. Isso pode explicar porque os diretores de falsos documentários de horror não costumam recorrer a esses modos de representação. espontânea. $\mathrm{O}$ enredo da maior parte desses filmes mostra pessoas tentando registrar algo (caso dos três estudantes de A bruxa de Blair, por exemplo) quando algum evento inesperado se sobrepõe ao objetivo inicial e ameaça suas vidas. O registro fílmico desse evento (ou, em alguns casos, da reação dos personagens ao evento) empresta o falso status de documento histórico a esse registro, algo que remonta diretamente aos modos de representação expositivo, observativo e participativo, conforme classificados por Bill Nichols (2005, p. 136).

Assim, podemos afirmar que os padrões estilísticos de imagem e som dos falsos documentários de horror são os mesmos que constituem a estilística dos documentários em que predominam esses modos de representação. Evidentemente, não se trata de coincidência. Os diretores de falsos found footage de horror desejam incluir em seus filmes, além de informações narrativas sobre uma história de ficção, um efeito de real reforçado pela aparência de documento histórico. Por isso, se esforçam para emular as ferramentas de estilo presentes nos documentários observativos e/ou participativos, cuja superfície estilística é mais reconhecível pelos espectadores ${ }^{6}$.

Diante dessas constatações, pode-se questionar qual o motivo (ou os motivos) de os filmes de horror terem passado, nos últimos anos, a usar a imperfeição técnica do registro imagético e sonoro como uma convenção narrativa capaz de produzir um efeito de real mais potente. A questão é complexa e merece uma reflexão detalhada, que não cabe nesse espaço, mas algumas das respostas possíveis passam, certamente, pelo caráter de testemunho histórico que é percebido, nas imagens produzidas de forma amadora, íntima ou espontânea, pelos espectadores. Este caráter é gerado ou reforçado pela existência de imperfeições técnicas simuladas a partir do princípio da câmera diegética.

Para Alexandra Heller-Nicholas (2011), o efeito de real gerado pela câmera diegética responde diretamente pelo resultado afetivo mais forte, obtido por falsos documentários de horror junto às audiências contemporâneas: 
A sensação de emoção e perigo resultante de assistir a um filme como A bruxa de Blair, [Rec] ou Atividade paranormal não decorre da dúvida ou da certeza sobre a veracidade das imagens, mas da construção formal das próprias imagens, pois esta construção sugere que, se houvesse imagens realmente verdadeiras nesses filmes, elas se pareceriam exatamente como são (HELLERNICHOLAS, 2011, p. 29).

Em outras palavras, parte do fascínio das ficções de horror codificadas como documentários de found footage está na estilística que simula o aspecto histórico das imagens e sons que compõem as obras. Para que esse fascínio se concretize, porém, é fundamental que a estilística do documentário seja devidamente reconhecida como tal. Daí a adesão deliberada dos cineastas à estética documental, imposta pelo princípio da câmera diegética. 


\section{Referências}

ALTMAN, R. Sound theory, sound practice. New York: Routledge, 1992. BARTHES, R. "O efeito de real”. In. BARTHES, R. O rumor da língua. São Paulo: Martins Fontes, 1972.

BORDWELL, D. Figuras traçadas na luz. Campinas: Papirus Editora, 2009.

. "Return to paranormalcy". Observations on film art. Publicado em 13 nov. 2012. Disponível em <http://www. davidbordwell.net/blog/2012/11/13/return-to-paranormalcy/>. Acesso em: 17 de fev. 2013.

The way Hollywood tells it: story and style in modern movies. Los Angeles: University of California Press, 2006.

BRASIL, A.; MIGLIORIN, C. "Biopolítica do amador: generalização de uma prática, limites de um conceito". Galáxia, São Paulo, n. 20, p. 84-94, dez. 2010.

CÁNEPA, L. L.; FERRARAZ, R. "Fantasmagorias das imagens cotidianas: o estranho e a emulação do registro videográfico doméstico no cinema de horror contemporâneo”. In: BRASIL, A.; Morettin, E; LISSOVSKY, M. Visualidades hoje. Salvador: Edufba, 2013.

CARREIRO, R. “Atividade paranormal”. Cine Repórter, 2010. Disponível em: <http:/www.cinereporter.com.br/criticas/atividadeparanormal>. Acesso em: 10 jul. 2013.

Era uma vez no spaghetti western: estilo e narrativa na obra de Sergio Leone. Tese (Doutorado) - Universidade Federal de Pernambuco, Recife, 2011.

CLOVER, C. J. Men, women, and chainsaws: gender in the modern horror film. New Jersey: Princeton University Press, 1992.

FELDMAN, I. "O apelo realista: uma expressão estética da biopolítica”. In: ENCONTRO ANUAL DA COMPÓS 17, São Paulo (Brasil), 2008. Anais eletrônicos... São Paulo, Unip, 2008. Disponível em: <http://www.compos.org.br/data/biblioteca_359. pdf $>$. Acesso em: 11 jul. 2013. 
GAULTIER, G. O documentário: um outro cinema. Campinas: Papirus, 2011.

HELLER-NICHOLAS, A. "Pre-history of 'Reality' horror film". Ol3Media (Università Roma Tre), v. 4, n. 9, p. 26-30, jan. 2011.

INGLE, Z. "George A. Romero's diary of the dead and the rise of the diegetic camera in recent horror films". In: Ol3Media (Università Roma Tre), v. 4, n. 9, p. 26-30, janeiro de 2011.

NICHOLS, B. Introdução ao documentário. Campinas: Papirus, 2005. ODIN, R. (Org.). Le film de famille: usage privé, usage public. Paris: Méridiens-Klincksieck, 1995.

PIEDADE, L. F. R. É tudo verdade? A exploração no documentário e o documentário de exploração. Tese (Doutorado) - Universidade de Campinas, Campinas (SP), 2007.

RAMOS, F.P. Mas afinal... o que é mesmo documentário?. São Paulo: editora Senac, 2008.

RHODES, G.D. "Mockumentaries and the production of realist horror”. Post-Script, v. 21, n. 3, p. 46-60, julho de 2002.

ROSCOE, J.; HIGHT, C. Faking it: mock-documentary and the subversion of factuality. Manchester: Manchester University Press, 2002.

SALT, B. Film style E technology: history and analysis. London: Stardword, 2009.

TARRAGÓ, O. "Exclusive interview with Oriol Tarragó". Designing Sound (blog). Publicado em 2010. Disponível em: $<\mathrm{http}$ ://designingsound.org/2010/04/exclusive-interview-with-orioltarrago-sound-designer-of-rec-and-rec-2/>. Acesso em: 10 jul. 2013.

WEST, A. "Caught on tape: the legacy of low-tech reality". In: KING, G. The spectacle of the real: from Hollywood to reality TV and beyond. Bristol: Intellect, 2005. 